\title{
Study on the wear mechanisms and rock destruction of core surface set bit in drilling for solid mineral exploration
}

\author{
Thao Xuan Nguyen ${ }^{1,}{ }^{*}$, Tuan Tran Nguyen ${ }^{2}$, Nam Van Le ${ }^{2}$ \\ ${ }_{1}$ Institute of Drilling Technology, Hanoi, Vietnam \\ ${ }^{2}$ Hanoi University of Mining and Geology, Hanoi, Vietnam
}

ARTICLE INFO ABSTRACT

Article history:

Received 18 ${ }^{\text {th }}$ Feb. 2021

Revised 25th May 2021

Accepted 12 $2^{\text {th }}$ June 2021

\section{Keywords:}

Diamond core bit,

Drilling technology,

Wear and friction of core bit.
In this paper, the authors present some research results of wearing process and rock destruction by diamond grit of core bit depending on drilling regime, rock hardness, diamond grit strength, etc. through the simulation of the interaction effect between diamond grit attached to the core bit and the rock. The relationship of the wear rate and rate of penetration of diamond core bit to the rotation per minute has been tested. On the basis of the research results, the authors have proposed solutions to select the appropriate technology for diamond drilling to improve the efficiency of solid mineral exploration in Vietnam.

Copyright (C) 2021 Hanoi University of Mining and Geology. All rights reserved.

${ }^{*}$ Corresponding author

E-mail: thao.vimsat@gmail.com

DOI: $10.46326 / J M E S .2021 .62(3 a) .04$ 


\title{
Tạp chí Khoa học Kỹ thuật Mỏ - Địa chất
}

\section{Nghiên cứu quá trình mòn và phá hủy đá bằng mũi khoan kim cương một lớp trong khoan thăm dò khoáng sản rắn}

\author{
Nguyễn Xuan Thảo ${ }^{1,}{ }^{*}$, Nguyễn Trần Tuan ${ }^{2}$, Lê Văn Nam ${ }^{2}$ \\ ${ }^{1}$ Viện Công nghệ Khoan, Hà Nội. Việt Nam \\ 2 Trường Đại học Mỏ - Địa chất, Hà Nội, Việt Nam
}

\begin{abstract}
THÔNG TIN BÀI BÁO
TÓM TẮT

Quá trình:

Nhận bài 18/02/2021

Sứa xong 25/5/2021

Chap nhận đăng 12/6/2021

Tùr khóa:

Công nghệ khoan,

Mòn và ma sát,

Mũi khoan kim cương.

Trong phạm vi bài báo, bằng phương pháp mô hình tác dụng tương hỗ giữa hạt kim cương gắn trong mũi khoan với đá, các tác giả trình bày một số kết quả nghiên cứu quá trình mòn và phá huỷ đá bằng hạt kim cương gắn trong mũi khoan phụ thuộc vào chế độ công nghệ khoan, độ cúng của đá, độ bền hạt kim cương,... Thử nghiệm xác lập mối quan hệ giứa cường độ mòn mũi khoan và vận tốc cơ học phụ thuộc vào tốc độ vòng quay. Trên cơ sở các kết quả nghiên cúu, bài báo đã đề xuất các giải pháp lựa chọn công nghẹ hợp lý khoan kim cương, nhằm nâng cao hiệu quả thăm dò khoáng sản rắn ở Việt Nam.
\end{abstract}

(C) 2021 Trường Đại học Mỏ - Địa chất. Tất cả các quyền được bảo đảm.

\section{Mở đầu}

Hiệu quả khoan các lỗ khoan thăm dò khoáng sản rắn phụ thuộc vào nhiều yếu tố, trong đó có độ bền của mũi khoan và chế độ công nghệ khoan hợp lý. Nhiều tài liệu nghiên cứu (Heinz, 2000; Soloviev, 1997; Neskoromnux, 2012) đã khẳng định: sử dụng mũi khoan kim cương và áp dụng chế độ công nghệ khoan hợp lý sẽ làm tăng năng suất, tăng tuổi thọ mũi khoan và giảm giá thành khoan. Hiện nay, mặc dù có các quan điểm khác nhau về việc lựa chọn cấu trúc mũi khoan kim cương cũng như chế độ công nghệ khoan hợp lý (Nguyễn Xuân Thảo, 2002; 2020; Heinz,

*Tác giả liên hệ

E - mail: thao.vimsat@gmail.com

DOI: 10.46326/JMES.2021.62(3a).04
2000; Soloviev, 1997), song các chuyên gia đều thống nhất: i) Quá trình phá huỷ đá trong khoan kim cương là một quá trình tác dụng tương hỗ giữa hạt kim cương gắn trong mũi khoan với đá, liên quan tới quá trình mòn hạt kim cương, mòn mũi khoan; quá trình ma sát, quá trình sinh nhiệt và tính chất cơ lý đá...; ii) Hiệu quả phá hủy đá và cường độ mòn của hạt kim cương gắn trong mũi khoan phụ thuộc vào tính chất cơ lý đá, chế độ công nghệ khoan, cấu trúc mũi khoan, độ bền của hạt kim cương và điều kiện môi trường tiếp xúc giữa mũi khoan với đá.

Trong phạm vi bài báo, bằng phương pháp mô hình tác dụng tương hỗ giữa hạt kim cương gắn trong mũi khoan với đá, nghiên cứu này sẽ góp phần làm sáng tỏ quá trình mòn và phá hủy đá bằng hạt kim cương. Trên cơ sở các kết quả nghiên cứu và thử nghiệm thực tế, các tác giả đề xuất giải pháp lựa chọn các thông số chế độ 
khoan hợp lý, phù hợp với điều kiện địa chất cụ thể nhằm mục đích nâng cao tuổi thọ mũi khoan, vận tốc cơ học khoan và giảm giá thành khoan.

\section{Nghiên cứu quá trình mòn và phá hủy đá bằng hạt kim cương gắn trong mũi khoan}

Khi nghiên cứu quá trình mòn và phá hủy đá trong khoan kim cương, các tác giả tiến hành theo hai hướng: i) nghiên cứu sự tác dụng tương hỗ giữa hạt kim cương với đá trong quá trình khoan (Heinz, 2000; Soloviev, 1997); ii) nghiên cứu sự tác dụng tương tác giữa một nhóm hạt kim cương gắn trong mũi khoan với đá trong quá trình khoan (Heinz, 2000; Soloviev, 1997).

Hạt kim cương gắn trong mũi khoan theo các sơ đồ khác nhau và độ nhô trên bề mặt đế khác nhau. Vì vậy, khi tác dụng với đá trong quá trình khoan sẽ tạo chiều dày lớp đá bị phá hủy cũng khác nhau. Mô hình tác dụng tương hỗ của một nhóm hạt kim cương trong quá trình phá hủy đá được mô tả ở Hình 1.

Từ Hình 1, nhận thấy các hạt kim cương gắn trong đế mũi khoan một lớp có kích thước khác nhau, độ nhô khác nhau tạo ra độ nháp trên mặt tiết diện đế mũi khoan. Trong quá trình khoan, các hạt kim cương tiếp nhận tải trọng chiều trục khác nhau, do đó chiều dày lớp đá bị phá hủy cũng khác nhau.

Trong quá trình khoan, nhờ tác dụng của tải trọng chiều trục và momen quay, hạt kim cương dịch chuyển và cắt đá. Chiều sâu trung bình cắt đá sau một vòng quay $h_{t b}(\mathrm{~m} /$ vòng) của các hạt kim cương tham gia phá hủy đá liên quan tới vận tốc cơ học được xác định theo công thức sau (Soloviev, 1997):

$$
h_{t b}=\frac{v_{m}}{n m}
$$

Trong đó: $v_{m}$ - vận tốc cơ học khoan, m/s; $n$ tốc độ vòng quay, v/phút; $m$ - số lượng hạt kim cương trong mũi khoan tham gia phá hủy đá.
Từ (1) cho thấy, việc nghiên cứu tác dụng tương hỗ giữa một nhóm hạt kim cương gắn trong mũi khoan với đá trong quá trình khoan rất phức tạp. Vì vậy, để làm sáng tỏ các yếu tố ảnh hưởng tới quá trình mòn và phá hủy đá trong khoan kim cương, hầu hết các chuyên gia đều theo hướng nghiên cứu tác dụng tương hỗ giữa hạt kim cương với đá trong quá trình khoan, sau đó bằng phương pháp nội suy sẽ tính toán chế độ làm việc của mũi khoan kim cương.

Quá trình tính toán mòn và hiệu quả phá hủy đá bằng hạt kim cương gắn trong mũi khoan được thực hiện trong điều kiện sau:

- Hạt kim cương dạng hình cầu bán kính $R_{a}$, làm việc trong điều kiện đá đồng nhất không nứt nẻ, độ cứng của đá $P_{s}$;

- Chế độ khoan hợp lý; mùn khoan tạo thành trong quá trình khoan được rửa sạch kịp thời không ảnh hưởng tới quá trình làm việc của hạt kim cương;

- Nhiệt độ sinh ra trong quá trình cắt đá được làm mát bằng nước rửa và không ảnh hưởng tới độ bền bề mặt tiếp của hạt kim cương với đá.

Mô hình tác dụng tương hỗ trong quá trình phá hủy đá bằng hạt kim cương được mô tả ở Hình 2. Dưới tác dụng của tải trọng chiều trục $P_{a}$ hạt kim cương xâm nhập vào đá và nén ép tạo vùng phá hủy với chiều sâu $h_{p}$; nhờ momen quay, hạt kim cương chuyển động và cắt đá với chiều dày lớp cắt $h$ bằng chiều sâu hạt kim cương xâm nhập vào đá; đồng thời trong quá trình cắt đá hạt cương cũng bị mòn với chiều cao $i$. Như vậy chiều dày thực tế lớp đá bị cắt $h_{t}$ được xác định:

$$
h_{t}=h-i
$$

Với: 1. hạt kim cương; 2 . đế mũi khoan; 3. vùng đá bị phá hủy; $P_{a}$ - tải trọng chiều trục tác dụng lên hạt kim cương, $\mathrm{N} ; h_{3}$ - khe hở giữa đế mũi khoan và đá, $\mathrm{m} ; h_{B}$ - đá, $\left.\mathrm{m}\right) ; h_{P}$ - chiều sâu lớp đá bị phá hủy, m; $i$ - chiều cao hạt kim cương

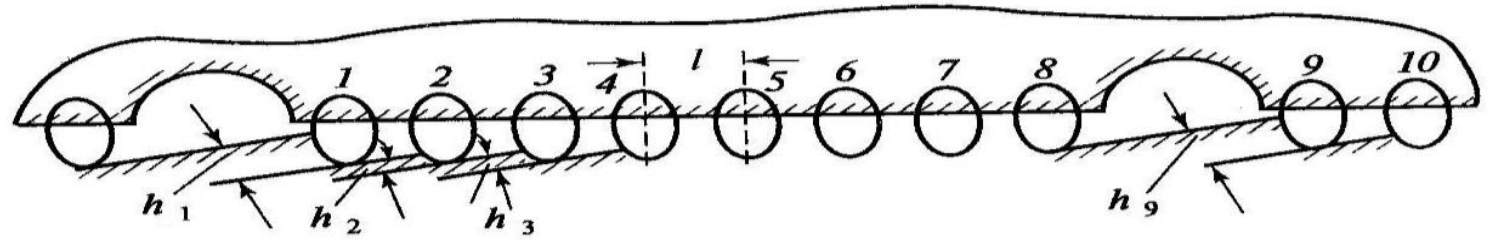

Hình 1. Mô hình tác dụng tương hỗ giũa nhóm hạt kim cương trong mũi khoan và đá trong quá trình khoan. 1 đến 10 - số thứ tự hạt kim cưong; $h_{1}, \ldots h_{9}$ - chiều sâu cắt đá; $l$ - khoảng cách giữa các hạt cắt. 


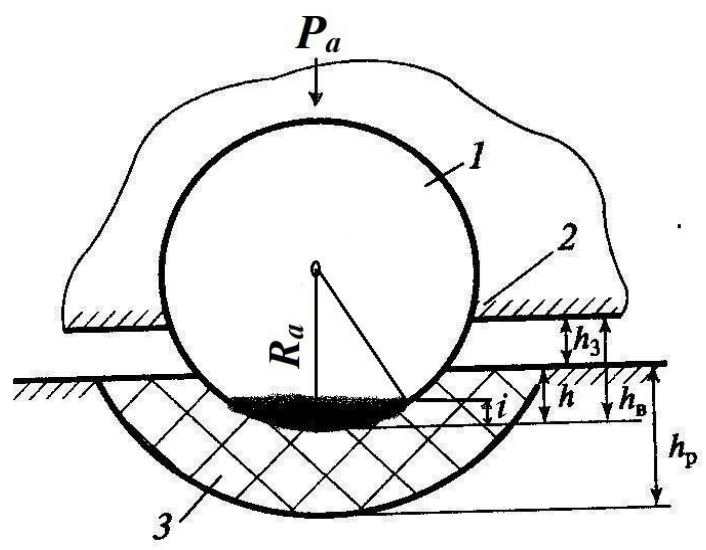

Hình 2. Mô hình tác dụng tương hỗ giữa hạt kim cưong và đá trong quá trình khoan.

bị mòn độ nhô của hạt kim cương, $\mathrm{m}$; $h$ - chiều dày lớp đá bị cắt; $m$ - chiều sâu xâm nhập của hạt kim cương vào.

Thể tích mòn hạt kim cương trong quá trình phá hủy đá xác định như sau:

$$
V_{a}=S_{a} i
$$

Trong đó: $V_{a^{-}}$thể tích mòn hạt kim cương, $\mathrm{m}^{3} ; S_{a^{-}}$diện tích tiếp xúc của hạt kim cương với đá, $\mathrm{m}^{2}$; $i$ - chiều cao mòn hạt kim cương, $\mathrm{m}$;

$$
S_{a}=\pi r^{2}
$$

Trong đó: $r$ - bán kính tiếp xúc của hạt kim cương với đá, $\mathrm{cm}$. Tù̀ Hình 2 có:

$$
r^{2}=R_{a}^{2}-\left(R_{a}-i\right)^{2}=2 R_{a} i-i^{2}
$$

Loại bỏ $i^{2}$ vì quá nhỏ so với $\mathrm{R}_{\mathrm{a}}$, vậy $r^{2}=2 R_{a} i$; thay giá $r^{2}$ vào biểu thức (4) ta có:

$$
S_{a}=2 \pi R_{a} i=\pi d_{a} i
$$

Từ đó ta có:

$$
V_{a}=\pi d_{a} i^{2}
$$

Công ma sát sinh ra trong quá trình mòn hạt kim cương được xác định theo công thức (Soloviev, 1997):

$$
A=f P_{a} V_{0} t
$$

Trong đó: $A$ - công sinh ra trong quá trình mòn hạt kim cương, $J$; $f$ - hệ số ma sát giữa hạt kim cương và đá; $P_{a}$ - tải trọng chiều trục tác dụng lên hạt kim cương, $\mathrm{N}$; $t$ - thời gian tiếp xúc của hạt kim cương với đá (thời gian khoan thuần túy), giây (s); $v_{0}$ - vận tốc chuyển động của hạt kim cương, $m / s$;

$$
v_{o}=\frac{\pi D n}{60}
$$

Trong đó: $D$ - đường kính trung bình của mũi khoan, $\mathrm{m} ; D=\frac{D_{1}+D_{2}}{2} ; D_{1}$ và $D_{2}$ - đường kính trong và ngoài của mũi khoan, $m$; $n$ - tốc độ vòng quay, v/phút.

Mặt khác công ma sát tỷ lệ với thể tích mòn hạt kim cương:

$$
A=M_{a} V_{a} \text { hay } V_{a}=\frac{A}{M_{a}}
$$

Trong đó: $M_{a}=4,05.1013 \mathrm{~J} / \mathrm{m}^{3}$ - độ bền mòn của hạt kim cương. So sánh (7) và (9), sau khi biến đổi ta có công thức xác định thể tích mòn $V_{a}$ như sau:

$$
V_{a}=\frac{\pi f P_{a} D n t}{60 M_{a}}
$$

So sánh với (10) và (6), sau khi rút gọn ta có:

$$
i=0,13 \sqrt{\frac{f P_{a} D n t}{d_{a} M_{a}}}
$$

Từ công thức (11) nhận thấy chiều cao mòn hạt kim cương trong quá trình phá huỷ đá là một hàm phức tạp phụ thuộc vào nhiều yếu tố: tốc độ vòng quay, tải trọng chiều trục, kích thuớc và độ bền mòn hạt kim cương gắn trong mũi khoan, kích thước mũi khoan, hệ số ma sát và thời gian khoan.

Nếu thay giá trị $P_{a}=\frac{P}{m}$ và $t=\frac{l_{k}}{v_{m}}$ vào công thức (11) sẽ xác định chiều cao mòn trung bình của các kim cương trong mũi khoan như sau:

$$
i_{t b}=0,13 \sqrt{\frac{f P D n l_{k}}{m d_{a} M_{a} v_{m}}}
$$

Trong đó $P$ - tải trọng chiều trục tác dụng lên mũi khoan, $\mathrm{N}$; $l_{k}$ - chiều dài hiệp khoan, $\mathrm{m} ; v_{m^{-}}$vận tốc cơ học khoan, m/s.

Nếu tính chiều dày cắt đá $h$ của hạt kim cương bằng $h_{t b}$ thì khi đó, thay giá trị $i_{t b}$ từ biểu thức (12) và giá trị $h_{t b}$ từ biểu thức (1) vào (2) sẽ xác định chiều được sâu thực tế cắt đá của các hạt kim cương gắn trong mũi khoan một lớp sau một vòng quay như sau:

$$
h_{t}=\frac{v_{m}}{n m}-0,13 \sqrt{\frac{f P D n l_{k}}{m d_{a} M_{a} v_{m}}}
$$




\section{Kết quả thử nghiệm và thảo luận}

Thử nghiệm trong điều kiện sản xuất nhằm mục đích xác lập sự phụ thuộc của vận tốc cơ học và mòn mũi khoan kim cương vào chế độ công nghệ khoan. Thử nghiệm được tiến hành tại lỗ khoan thăm dò than ở Mạo Khê, Quảng Ninh trong tầng đá cát kết liền khối ở chiều sâu $93 \div 100 \mathrm{~m}$; độ cứng của đá cấp $\mathrm{X}$ theo bảng phận cấp đất đá theo độ khoan. Dung dịch dùng để rửa lỗ khoan là dung dịch ít sét điều chế từ bột sét bentonit; các thông số dung dịch: tỷ trọng $\gamma=$ $1,05 \div 1,1 \mathrm{~g} / \mathrm{cm}^{3}$, độ nhớt $T=19 \div 20 \mathrm{~s}$, độ thải nước $B=6 \div 8 \mathrm{~cm}^{3} / 30$ phút; mũi khoan dùng khoan thử nghiệm là mũi khoan kim cương 1 lớp của Trung Quốc đường kính 76 mm; chế độ công nghệ khoan: tải trọng chiều trục tác dụng mũi khoan $P=10.000 \mathrm{~N}$; vận tốc vòng quay $n=200$ $\mathrm{v} /$ phút, $400 \mathrm{v} /$ phút, $600 \mathrm{v} /$ phút và $800 \mathrm{v} /$ phút. Từ các kết quả thử nghiệm đã xây dựng được đồ thị sự phụ thuộc vận tốc cơ học $v_{m}$ và mòn mũi khoan $J$ vào tốc độ vòng quay (Hình 3 ).
Từ đồ thị (Hình 3) cho thấy, khi tốc độ vòng quay $n$ nằm trong khoảng $200 \div 400 \mathrm{v} /$ phút (vùng I), vận tốc cơ học tăng nhanh; cường độ mòn tăng dần theo qui luật tuyến tính; ở vùng II, khi tốc độ vòng quay tăng $400 \div 600 \mathrm{v} /$ phút, vận tốc cơ học hầu như không tăng và có xu hướng giảm dần; trong khi đó, cường độ mòn mũi khoan tăng dần. Ở vùng III, khi tốc độ vòng quay tăng lớn hơn 600 v/phút vận tốc cơ học giảm một cách rõ rệt; đồng thời cường độ mòn của mũi khoan cũng tăng nhanh không tuân theo qui luật tuyến tính. Như vậy, trong giới hạn tốc độ vòng quay hợp lý, vận tốc cơ học tăng nhanh, cường độ mòn của mũi khoan tăng theo qui luật tuyến tính. Khi tốc độ vòng quay vượt quá giới hạn hợp lý, vận tốc cơ học giảm dần và cường độ mòn sẽ tăng nhanh. Khi đánh giá hiệu quả phá hủy đá trong khoan kim cương, các chuyên gia đều dựa vào chỉ tiêu tiến độ của mũi khoan sau một vòng quay. Theo quan điểm của các chuyên gia (Heinz, 2000; Soloviev, 1997) đây là chỉ tiêu không chỉ phản ánh thực chất của quá trình phá hủy đá bằng mũi

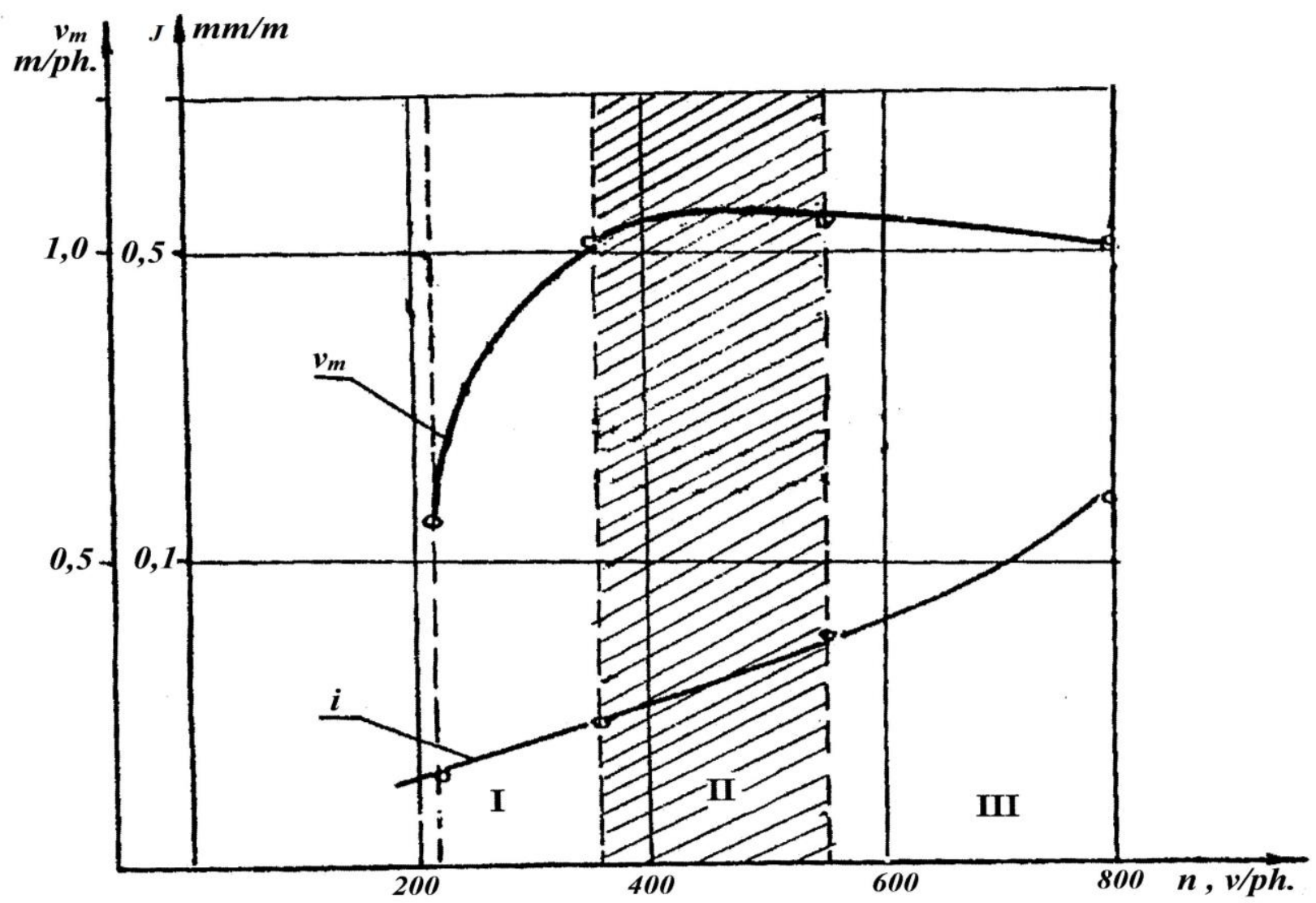

Hình 3. Sự phụ thuộc vận tốc cơ học khoan v và cường độ mòn J của mũi khoan một lớp đường kính 76 mm vào tốc độ vòng quay khi khoan đá cát kết ở Mạo Khê, Quảng Ninh. 
khoan kim cương mà còn là chỉ tiêu tổng hợp liên quan tới tính chất cơ lý của đá, các thông số chế độ khoan và cấu trúc mũi khoan.

Từ biểu thức (1) cho thấy, trong trường hợp số lượng hạt kim cương gắn trong mũi khoan tham gia phá hủy đá không thay đổi; tiến độ trung bình của mũi khoan $h_{\text {tb }}$ tăng chỉ có thể xảy ra khi: i) vận tốc cơ học tăng thì tốc độ vòng quay không tăng hoặc giảm; ii) vận tốc cơ học trong quá trình khoan không thay đổi, nhưng tốc độ vòng quay giảm. Trong các trường hợp này, hiệu quả phá huỷ đá tăng chủ yếu do tăng tải trọng chiều trục tác dụng lên mũi khoan; nhưng khi tăng tải trọng chiều trục, khe hở giữa mặt tiếp xúc của đế mũi khoan với đá giảm, làm cản trở quá trình thoát mùn khoan. Từ đó dẫn tới hiện tượng "bó mùn khoan", tăng nhiệt độ bề mặt tiếp xúc làm tăng độ mòn của hạt kim cương và đế mũi khoan. Nếu tiếp tục tăng tải trọng tác dụng lên mũi khoan, vận tốc khoan sẽ giảm và cường độ mòn mũi khoan sẽ tăng. Tiến độ trung bình $h_{t b}$ của mũi khoan không thay đổi khi mức độ tăng vận tốc cơ học và tốc độ vòng quay như nhau. Trong trường hợp này $h_{t b}$ sẽ đạt tới giá trị tối ưu, nghĩa là các thông số chế độ khoan đã lựa chọn phù họp với tính chất cơ lý đá và đảm bảo cho mũi khoan phá hủy đá trong điều kiện "phá huỷ thể tích".

Ngược lại, tiến độ trung bình $h_{t b}$ của mũi khoan sau một vòng quay giảm có thể do: i) vận tốc vòng quay tăng mà vận tốc cơ học không tăng hoặc không thay đổi; ii) vận tốc vòng quay không tăng nhưng vận tốc cơ học giảm. Nguyên nhân chủ yếu của các trường hợp này là do lựa chọn tải trọng chiều trục tác dụng lên mũi khoan và vận tốc vòng quay chưa phù hợp, không đảm bảo độ tiến sâu của hạt cắt trong mũi khoan vào đá; dẫn tới mũi khoan làm việc ở chế độ mài mòn. Tại bề mặt tiếp xúc không xảy ra hiện tượng phá huỷ thể tích, do đó hiệu quả phá huỷ đá bị giảm và cường độ mòn mũi khoan tăng.

\section{Kết luận}

Từ các kết quả nghiên cứu có thể rút ra một số kết luận cơ bản sau:

- Chiều cao mòn hạt kim cương gắn trong mũi khoan một lớp phụ thuộc vào chế độ khoan, kích thước và độ bền mòn hạt kim cương gắn trong mũi khoan, kích thước mũi khoan, hệ số ma sát và thời gian khoan.
- Sự phụ thuộc vận tốc cơ học, cường độ mòn mũi khoan trong khoan kim cương với tốc độ vòng quay là sự phụ thuộc tương phản khi tăng tốc độ vòng quay, vận tốc cơ học tăng nhanh đồng thời cường độ mòn mũi khoan cũng tăng nhưng với mức độ chậm. Nếu tiếp tục tăng tốc độ vòng quay và vận tốc cơ học giảm, cường độ mòn mũi khoan tăng nhanh.

- Ở vùng Quảng Ninh, khi khoan bằng mũi khoan kim cương một lớp đường kính 76 mm trong đá cát kết độ cứng cấp X theo độ khoan, nên áp dụng chế độ khoan với tải trọng chiều trục $10.000 \mathrm{~N}$, tốc độ vòng quay của bộ dụng cụ khoan trong khoảng $350 \div 550$ v/phút;

- Kết quả nghiên cứu tác dụng tương hỗ giữa hạt kim cương và đá sẽ giúp hiểu rõ bản chất của quá trình mòn và phá hủy đá. Trên cơ sở đó sẽ lựa chọn cấu trúc mũi khoan, chế độ công nghệ khoan kim cương hợp lý phù hợp với thực tế từng loại đá.

\section{Lò̀i cảm ơn}

Nhóm tác giả xin chân thành cảm ơn TS. Nguyễn Duy Tuấn, Viện Công Nghệ Khoan đã có những giúp đỡ quý báu về học thuật cũng như cơ sở nghiên cứu; xin chân thành cảm ơn Công ty than Mạo Khê - TKV đã giúp đỡ và hộ trợ công tác thử nghiệm khoan được tiến hành thuận lợi và thu được nhiều kết quả.

\section{Đóng góp của các tác giả}

Tác giả Nguyễn Xuân Thảo nghiên cứu cơ chế mòn hạt kim cương trong quá trình cắt đá của lưỡi khoan và đề xuất giải pháp hạn chế sự mòn. Nguyễn Trần Tuân và Lê Văn Nam chịu trách nhiệm áp dụng thử nghiệm lý thuyết vào thực tiễn khoan ở Mỏ Mạo Khê và tổng hợp số liệu.

\section{Tài liệu tham khảo}

Nguyễn Xuân Thảo, Nguyễn Trương Tú, (2002). Nghiên cứu một số biện pháp nâng cao tốc độ cơ học trong khoan kim cương tốc độ vòng quay lớn. Tuyển tập báo cáo Hội nghị khoa học lần thú 15. Đại học Mỏ - Địa chất, Hà Nội. 5258.

Nguyễn Xuân Thảo, Trần Văn Bản, Trần Đình Kiên, Nguyễn Thế Vinh, Nguyễn Duy Tuấn, Nguyễn Trần Tuân, Nguyễn Văn Thịnh, 
Nguyễn Thị Thục Anh. (2020). Công nghệ khoan thăm dò. Nhà xuat bản Khoa học và Kỹ thuật, Hà Nội. 698 tr.

Soloviev N. V., Trikhotkin V. F., Bogdanov R. K., Zakora A. P. (1997). Công nghệ khoan kim cương trong điều kiện địa chất phức tạp. VNIIOENG. Mátx-Cơ-Va. 332 trang. Соловьев Н. В., Чихоткин В.Ф., Богданов Р. К., Закора А.П., (1997). Ресурсосберегающая технология алмазного бурения в сложных геологических условиях. ВНИИОЭНГ
Москва. 332 с.

Heinz W. F. (2000). Diamond drilling hanbook. South Africa. 538 pages.

Neskoromnux V. V. (2012). Nguyên lý phá huỷ đất đá trong công tác thăm dò. Đại học Tổng hợp Ciberia. Krasnodar. 300 trang. Нескоромных В.В. (2012). Разрушение горных пород при проведении геологоразведочных работ. Красноярск. СФУ. 300 с. 